\title{
Gut Microflora Associated with Adult Dung Beetles Oniticellus cinctus and Onthophagus dama (Coleoptera: Scarabaeidae)
}

\author{
Surabhi Kumari*, R. Rangeshwaran, A.N. Shylesha and Jagadeesh Patil
}

ICAR- National Bureau of Agricultural Insect Resources, P.B. No. 2491, HA Farm Post, Bellary Rd, Hebbal, Bengaluru, Karnataka-560024, India

*Corresponding author

\section{A B S T R A C T}

\begin{tabular}{|l|}
\hline Key w or d s \\
$\begin{array}{l}\text { Diversity, Dung beetles, } \\
\text { Onthophagus dama, } \\
\text { Oniticellus cinctus, Gut } \\
\text { bacteria, 16s rDNA }\end{array}$ \\
\hline Article Info \\
\hline $\begin{array}{l}\text { Accepted: } \\
\text { 07 February } 2018 \\
\text { Available Online: } \\
\text { 10 March } 2018\end{array}$ \\
\hline
\end{tabular}

Dung beetles gut harbour various microorganisms providing benefits to the host as well as to the environment. Experiments were conducted to identify the bacterial diversity associated with gut of the adult dung beetles Onthophagus dama and Oniticellus cinctus through culture dependent as well as culture independent method. Eight culturable bacterial isolates were isolated from the gut of $O$. cinctus and ten isolates from $O$. dama. Metagenomics research has been developed over the past decade to elucidate the genomes of the uncultured microorganisms with an aim of understanding microbial ecology. Hence metagenomics studies were also done by traditional 16s rDNA cloning resulted in identification of uncultured Enterobacter sp., uncultured Aeromonas sp., uncultured Ralstonia sp., uncultured Dysgonomonas sp., uncultured beta proteobacterium form $O$. dama and uncultured Enterococcus sp., uncultured Firmicutes bacterium, uncultured Gilliamella sp., uncultured Peptoniphilaceae, uncultured Dysgonomonas sp., uncultured Burkholderiales bacterium, uncultured Porphyromonas sp., uncultured Gilliamella sp. from gut of $O$. cinctus which were reported for the first time.

\section{Introduction}

Dung beetles (Coleoptera; Scarabaeidae) play very important role in the wellbeing of our planet. They improve nutrient recycling and soil structure (Brown et al., 2010). The habitats of dung beetles are diverse which includes, farmland, grasslands, desert and forest (Losey and Vaughan, 2006; Nichols et al., 2008). The gut microbiota of insects plays crucial roles in the growth, development and environmental adaptation to the host insects. The gut of insects contain 10 times more microbes than total cells of the insect and 100 folds more microbial genes than animal genes (Rajagopal, 2009) which will have important role in digestion as well as metabolism and mostly advantageous to the host. As they feed on dung and dung is the undigested residue of plant matter it is possible that dung beetles will be having the microflora present in the gut which helps in digestion of complex carbohydrates. Hence it is very important to know the total microflora present in the gut of these beetles. Metagenomic, the study of metagenome will help us identification the genomes of all microorganisms from different environmental samples. As culture dependant 
technique will not reveal the entire bacterial community present in the gut (Gilliam, 1997). Hence, Metagenomics can make it possible to relate potential function of the specific microorganisms within the gut communities. As research on gut microflora of adult dung beetles Onthophagus dama (Fab.) and Oniticellus cinctus (Fab.) has not been reported yet. In this study, the total microbial diversity was studies from adult dung beetles $O$. dama and $O$. cinctus. It is possible that these gut microbes associated with the beetle may degrade complex organic matter, which is the future aspect of the work.

\section{Materials and Methods}

\section{Dung beetles collection and dissection of} insect gut

Dung beetles (Oniticellus cinctus and Onthophagus dama) were collected from a dairy farm located in the district of Bengaluru, Karnataka, India and kept in aerated container. Identity was confirmed by Dr. K. Veenakumari, Principal Scientist and taxonomist, ICAR-NBAIR, Bengaluru. The adult beetles were maintained live using cow dung as medium. The collected beetles were starved overnight, so that gut remains clear of any food particle. The insect was surface sterilized twice with $70 \%$ ethanol for $1 \mathrm{~min}$ and washed with distilled water. Entire gut was aseptically removed in a UV laminar flow hood. The isolated gut was kept in $10 \mathrm{mM}$ phosphate buffer and minced with the help of sterile micro pestle (Vasanthakumar et al., 2006).

\section{Culture dependant method}

\section{Isolation of gut microflora}

The gut extracts collected were serially diluted and spread plated on Nutrient agar (NA), yeast peptone dextrose adenine agar (YPDA), potato dextrose agar (PDA). Plates were incubated at $37^{\circ} \mathrm{C}$ for $48 \mathrm{hrs}$. All chemicals used for media preparation were acquired from HiMedia Laboratories Pvt. Ltd. The bacterial isolates were differentiated based on their gram's nature.

\section{S rDNA analysis}

The bacterial DNA was extracted using Hipura Himedia genomic DNA extraction kit. Universal primer fd1 and $\mathrm{rp} 2$ were used for $16 S$ rDNA PCR. The PCR reaction conditions consisted of an initial denaturation step at $94^{\circ} \mathrm{C}$ for 3 mins, final denaturation at $94^{\circ} \mathrm{C}$ for $1 \mathrm{mins}$, annealing at $45^{\circ} \mathrm{C}$ for $1 \mathrm{~min}$, extension at $72^{\circ} \mathrm{C}$ for $2 \mathrm{~min}$, and a final extension cycle at $72^{\circ} \mathrm{C}$ for 10 mins, 35 cycles. The generated sequences were compared with sequences available in GenBank by using the BLASTn program (http://www.ncbi.nih.gov) (Shayne et al., 2003). The sequences were aligned using BioEdit alignment editor and sequences were submitted to Genbank to get the accession numbers.

\section{Culture independent method}

\section{Isolation of metagenomic DNA}

Isolation of genomic DNA from gut of dung beetles, $O$. cinctus and $O$. dama was done using cell and tissue DNA kit (magspin 35, APS Lifetech, India) method as described by manufacturer in kit instruction manual. Isolated DNA was checked using 1\% agarose gel electrophoresis and it was documented (GelDoc-XR, Bio-Rad Laboratories, Inc.). The concentration of DNA was estimated using 260/280 nm absorbance using UV-Vis spectrophotometer (HITACHI U-2910).

\section{PCR amplification of $16 S$ rDNA and gene cloning}

PCR of the bacterial $16 \mathrm{~S}$ rDNA was performed using universal eubacterial primers 27F/806R. This pair of PCR primers generated 
around 790 bp PCR products upon successful amplification. Every PCR reaction mixture contained 5.0 uL of genomic DNA; $10 \mathrm{pM}$ of each primer; $200 \mathrm{pM}$ (each) dATP, dCTP, $\mathrm{dGTP}$ and dTTP; and $1.0 \mathrm{U}$ of Taq DNA polymerase in the PCR buffer provided in the kit. Reaction products were analyzed by electrophoresis through $2 \%(\mathrm{~W} / \mathrm{V})$ agarose (Promega Corporation, Madison, WI 53711 USA) gel slabs $(10 \mathrm{~cm}$ by $16 \mathrm{~cm}$ by $6 \mathrm{~mm}$ ) with $0.5 x$ Tris-borate- EDTA buffer. Gels were stained with ethidium bromide, placed over a source of UV light, and then photographed. The molecular sizes of PCR amplicons, relative to molecular size standards scale 100bp (APS LABS, Pune) were determined. The PCR product was purified using APS LABS PCR purification kit to remove unused dNTPs and primers. Cloning of $16 \mathrm{~S}$ rDNA amplicons was performed using Promega TA cloning kit consisting of pGEMT vector and $E$. coli XL1 blue Chemical competent cells. The TA Cloning reaction $(10.0 \mu \mathrm{L})$ for eventual transformation into chemically competent E.coli XL1 blue cells was performed as: Fresh PCR product $3.0 \mu \mathrm{L}$, pGEMT Vector $1.0 \mu \mathrm{L}$, T4 DNA ligase 1.0 $\mu \mathrm{L}, 10 \mathrm{x}$ Ligation buffer $1.0 \mu \mathrm{L}$ and Final Volume $10.0 \mu \mathrm{L}$. The reaction was mixed gently and incubated for Overnight at $4-8^{\circ} \mathrm{C}$ temperature. After Screening of transformants colony, each colony was further subjected to boiling lysis followed by colony PCR using T7 and SP6 Primers.

\section{Bioinformatics analysis and phylogenetic tree construction}

The sequences were subjected to search analysis Basic Local Alignment Search Tool (http://www.ncbi.nih.gov) to identify sequences of the highest similarity and submitted to Genbank to obtain accession numbers for each sequences. Respective Bioproject and Biosamples were created for both the dung beetles. The phylogenetic tree was constructed using maximum likelihood method using Molecular Evolutionary Genetics Analysis version 6 (MEGA6) program based on Kimura-2 parameters with 1000 replicates of bootstrap values.

\section{Results and Discussion}

\section{Isolation and identification of isolates}

Upon plating the gut contents of $O$. cinctus and $O$. dama on different nutrient media, 8 bacteria were isolated from $O$. cinctus and 10 isolates from $O$. dama as unique isolates and assigned strain numbers. Initial characterization showed both were Gram positive as well as negative isolates. The purified cultures from both the beetles were identified by $16 \mathrm{~S}$ rDNA sequence analysis. The analysis identified the eight isolates from Oniticellus cinctus as Acinetobacter baumannii (OS5.1), Staphylococcus saprophyticus (OS5.2), Enterobacter ludwigii (OS5.4), Enterobacter cloacae (OS5.6), Bacillus cereus (OS8.2), Ralstonia mannitolilytica (OS8.6), Stenotrophomonas maltophilia (OS10.8)and nine isolates from Onthophagus dama as Bordetella avium (DHN10.2), Achromobacter marplatensis (DHN10.3), Bacillus aerophilus (DHN10.4), Achromobacter xylosoxidans (DMN8.4), Bacillus tequilensis (DFY8.16), Achromobacter piechaudii (DMN8.7), Bacillus safensis (DMN8.1), Bacillus licheniformis (DFN8.3), Bacillus subtilis (DMY8.15). The identified bacteria showed 96-100\% nucleotide homology with other bacterial strains available in the NCBI database and the sequences were submitted to NCBI (Table 1).

Though studies on the type of microbes inhabiting the digestive tract of scarab beetles have been well documented (Cazemier et al., 2003; Egert et al., 2005; Zhang and Jackson 2008); the type of bacteria inhabiting the digestive tract of adult beetles is limited or not available. 
Fig.1 Molecular phylogenetic analysis of unculturable microflora from Onthophagus dama and Oniticellus cinctus gut by maximum likelihood method using 16S rRNA gene sequences of NCBI GenBank. The numbers at branch points of the tree designate boot strap values

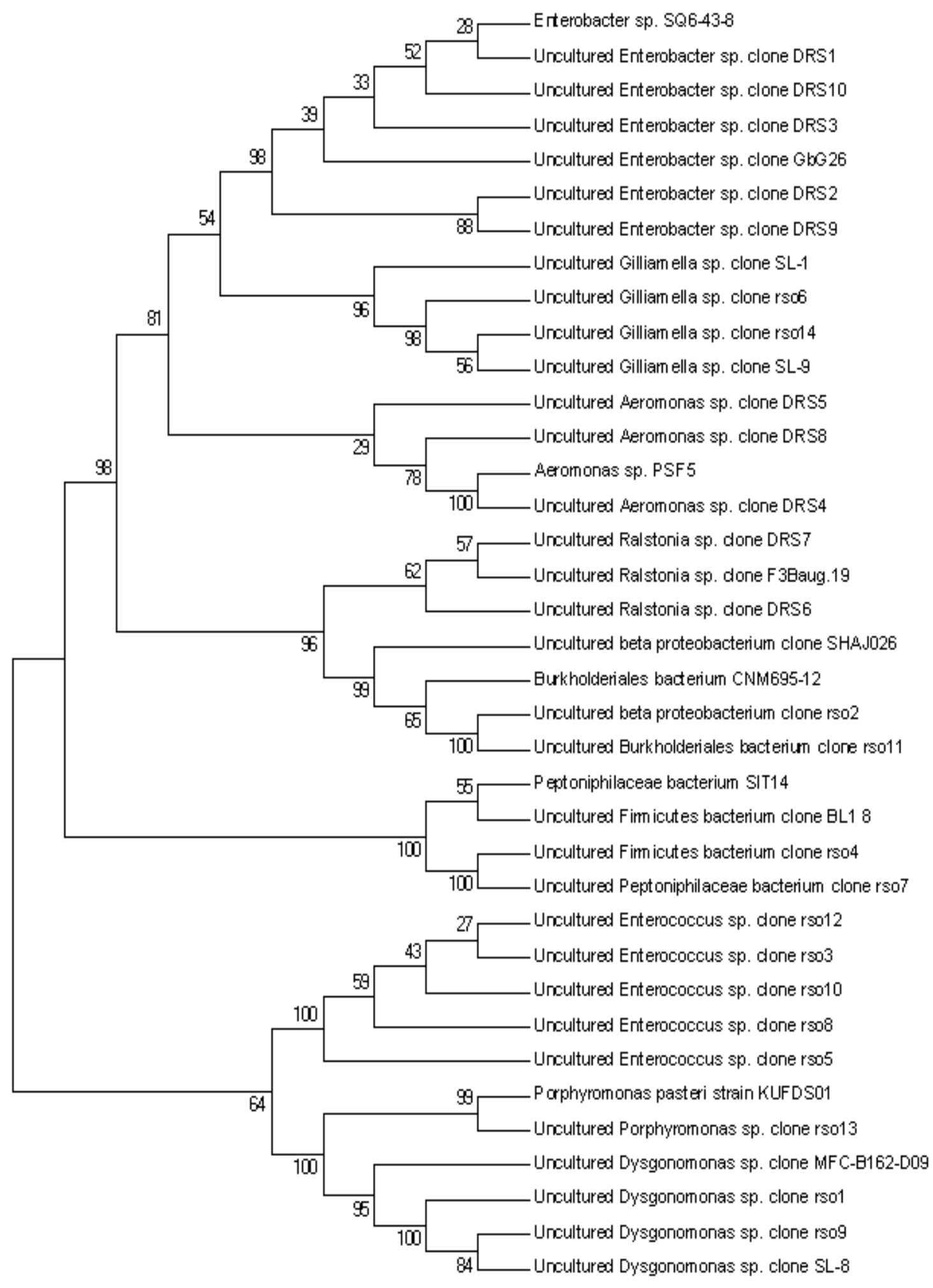


Table.1 Closest BLASTn matches for the 16S rDNA bacterial sequences in GenBank and accession number of each strain

\begin{tabular}{|c|c|c|c|c|}
\hline Host & Culture type & Strain & Most similar species & Accession No. \\
\hline \multirow{8}{*}{$\begin{array}{l}\text { Oniticellus } \\
\text { cinctus }\end{array}$} & Culturable & OS5.1 & Acinetobacter baumannii & KX242271 \\
\hline & Culturable & OS5.2 & Staphylococcus saprophyticus & KX242270 \\
\hline & Culturable & OS5.4 & Enterobacter ludwigii & KX242269 \\
\hline & Culturable & OS5.6 & Enterobacter cloacae & KX242268 \\
\hline & Culturable & OS8.2 & Bacillus cereus & KX242264 \\
\hline & Culturable & OS8.6 & Ralstonia mannitolilytica & KX242263 \\
\hline & Culturable & OS10.6 & Kocuria koreensis & KX242261 \\
\hline & Culturable & OS10.8 & Stenotrophomonas maltophilia & KX242259 \\
\hline \multirow{10}{*}{$\begin{array}{l}\text { Onthophagus } \\
\text { dama }\end{array}$} & Culturable & DHN10.2 & Bordetella avium & KP984765 \\
\hline & Culturable & DHN10.3 & Achromobacter marplatensis & KP984766 \\
\hline & Culturable & DHM10.4 & Bacillus aerophilus & KX809598 \\
\hline & Culturable & DMN8.4 & Achromobacterxylosoxidans & KT853099 \\
\hline & Culturable & DFY8.16 & Bacillus tequilensis & KT853100 \\
\hline & Culturable & DMN8.7 & Achromobacter piechaudii & KT853101 \\
\hline & Culturable & DMN8.1 & Bacillus safensis & KX809601 \\
\hline & Culturable & DFN8.3 & Bacillus licheniformis & KX809603 \\
\hline & Culturable & DMY8.15 & Bacillus subtilis & KT853098 \\
\hline & Culturable & DHN10.1 & Bacillus pumilus & KX809597 \\
\hline \multirow{10}{*}{$\begin{array}{l}\text { Onthophagus } \\
\text { dama }\end{array}$} & Unculturable & DRS1 & Uncultured Enterobacter sp. & KX585900 \\
\hline & Unculturable & DRS2 & Uncultured Enterobacter sp. & KX585902 \\
\hline & Unculturable & DRS3 & Uncultured Enterobacter sp. & KX585903 \\
\hline & Unculturable & DRS4 & Uncultured Aeromonas sp. & KX585904 \\
\hline & Unculturable & DRS5 & Uncultured Aeromonas sp. & KX585905 \\
\hline & Unculturable & DRS6 & Uncultured Ralstonia sp. & KX585906 \\
\hline & Unculturable & DRS7 & Uncultured Ralstonia sp. & KX585907 \\
\hline & Unculturable & DRS8 & Uncultured Aeromonas sp. & KX585908 \\
\hline & Unculturable & DRS9 & Uncultured Enterobacillus sp. & KX585909 \\
\hline & Unculturable & DRS10 & Uncultured Enterobacter sp. & KX585910 \\
\hline \multirow{14}{*}{$\begin{array}{l}\text { Oniticellus } \\
\text { cinctus }\end{array}$} & Unculturable & RSO1 & Uncultured Dysgonomonas sp. & KX523835 \\
\hline & Unculturable & $\mathrm{RSO} 2$ & Uncultured beta proteobacterium & KX523836 \\
\hline & Unculturable & RSO3 & Uncultured Enterococcus sp. & KX523837 \\
\hline & Unculturable & RSO4 & Uncultured Firmicutes bacterium & KX523838 \\
\hline & Unculturable & RSO5 & Uncultured Enterococcus sp. & KX523839 \\
\hline & Unculturable & RSO6 & Uncultured Gilliamella sp. & KX523840 \\
\hline & Unculturable & RSO7 & Uncultured Peptoniphilaceae bacterium & KX523841 \\
\hline & Unculturable & RSO8 & Uncultured Enterococcus sp. & KX523842 \\
\hline & Unculturable & RSO9 & Uncultured Dysgonomonas sp. & KX523843 \\
\hline & Unculturable & RSO10 & Uncultured Enterococcus sp. & KX523847 \\
\hline & Unculturable & RSO11 & Uncultured Burkholderiales bacterium & KX523844 \\
\hline & Unculturable & RSO12 & Uncultured Enterococcus sp. & KX523845 \\
\hline & Unculturable & RSO13 & Uncultured Porphyromonas sp. & KX523846 \\
\hline & Unculturable & RSO14 & Uncultured Gilliamella sp. & KX523848 \\
\hline
\end{tabular}


It is assumed that adults will pass on some of these bacteria to its progeny and some could be acquired from the environment.

\section{Identification of culture independent bacteria}

The 16S rRNA profiling studies have provided indispensable understanding into the taxonomic composition of the gut microflora, which in turn has facilitated the inference of broad evolutionary patterns. Amplification specific to $16 \mathrm{~S}$ rDNA gene reveals size of the PCR amplicons near around $790 \mathrm{bp}$. The pGEMT cloning vector DNA with cloned insert shows an amplicon of $175+800=975$ bp. The empty vectors that do not contain insert show amplicons of size $175 \mathrm{bp}$. Total ten clones were selected from $O$. dama and fourteen clones were selected from $O$. Cinctus.

To the total microbes present in the environment more than 90\% microflora cannot be cultured and hence yet unrevealed. From this study pertaining to unculturable microflora, we reported bacterial isolates Gilliamella sp. belonging to Gammaproteobacteria from gut of $O$. cinctus. This isolate has been also reported from honey bee (Aphis mellifera) as well as bumble bees (Bombus bimaculatus) gut (Kwong and Moran 2013), which has role in detoxification of toxic carbohydrates present in honeybee diet (Zheng et al., 2016). Enterococcus sp. is dominant bacterial group in insects and was seen in both the beetles (O. dama and $O$. cinctus). Enterococcus sp. was also reported to be associated with guts of Gypsy moth (Allen et al., 2009), S. litura (Tang et al., 2012). We have also identified Enterobacter sp., Aeromonas sp., Ralstonia sp., Dysgonomonas sp., beta proteobacterium form $O$. dama and Firmicutes bacterium, Peptoniphilaceae, Dysgonomonas sp., Burkholderiales bacterium, Porphyromonas sp., from gut of $O$. cinctus, which is also the first report on these dung beetles.

\section{Phylogenetic analysis}

Phylogenetic analysis methods like maximum likelihood (ML), maximum parsimony (MP), neighbour-joining (NJ), minimum evolution (ME), UPGMA and Bayesian approach are used by different workers (Sriram et al., 2013). ME gives more importance to the recent process of evolutionary variations. The MEGA 6 programme was used for phylogenetic tree construction with 1000 bootstrap value (Fig. 1). The maximum likelihood tree was constructed to see the phylogenetic relationship of the sequences obtained in this study with its closest strain from Genbank database (GenBank, NCBI) (Table 1). The phylogenetic analysis of all bacterial isolates was performed after editing the sequences using multiple alignments. The analysis involved 37 nucleotide including test and reference sequences in culture independent approach. All positions with less than $95 \%$ site coverage were eliminated. That is, fewer than 5\% alignment gaps, missing data, and ambiguous bases were allowed at any position. Two genetic groups were formed from 24 bacterial strains from $O$. cinctus and $O$. dama gut. Group I represented 16 bacterial isolates with $>99 \%$ similarity (Enterobacter sp. DRS1, Enterobacter sp. DRS2, Enterobacter sp. DRS3, Enterobacter sp. DRS9, Enterobacter sp. DRS10, Gilliamella sp. RSO6, Gilliamella sp. RSO14, Aeromonas sp. DRS5, Aeromonas sp. DRS8, Aeromonas sp. DRS4, Ralstonia sp. DRS6, Ralstonia sp. DRS7, beta proteobacterium RSO2, Burkholderiales bacterium RSO11, Firmicutes bacterium RSO4, Peptoniphilaceae bacterium RSO7). Group II consisted of 8 isolates with $>97 \%$ similarity (Enterococcus sp. RSO12, Enterococcus sp. RSO3, Enterococcus sp. RSO10, Enterococcus sp. RSO8, Enterococcus sp. 
RSO5, Porphyromonas sp. RSO13 Dysgonomonas sp. RSO1, Dysgonomonas sp. RSO9) (Table 1).

\section{Nucleotide Accession numbers}

The sequence obtained were deposited to Genbank under the accession numbers KX523835-KX523848, Bioproject PRJNA321463, Biosample SAMN05001291 in case of $O$. cinctus and accession numbers KX585900, KX585902-KX585910, Bioproject PRJNA329583, Biosample SAMN05415091 in case of O. Dama.

\section{Acknowledgments}

The authors are thankful to ICAR- National Bureau of Agricultural Insect Resources, Bengaluru, Karnataka, India for providing necessary facilities to carry out this research work.

\section{References}

Allen, H.K., Cloud-Hansen, K.A., Wolinski, J.M., Guan, C., Greene, S., Lu, S., Boeyink, M., Broderick, N.A., Raffa, K.F., Handelsman, J. 2009. Resident microbiota of the gypsy moth midgut harbors antibiotic resistance determinants. DNA Cell Biol. 28: (3), 109-117.

Brown, J., Clarke, H.S., Janeau, J.L., Grellier, S., Podwojewski, P. 2010. Dung beetles (Coleoptera: Scarabaeidae) can improve soil hydrological properties. Appl. Soil. Ecol. 46: 9-16.

Cazemier, A.E., Verdoes, J.C., Reubsaet, F.A.G., Hackstein, J.H.P., vander Drift, C., Opden Camp, H.J.M. 2003. Promicromonospora pachnodae sp. nov., a member of the (hemi) cellulolytic hindgut flora of larvae of the scarab beetle Pachnoda marginata. Antonie Leeuwenhoek. 83:135-148.
Egert, M., Stingl, U., Dyhrberg, B.L., Wagner, B., Brune, A., Friedrich, M.W. 2005. Structure and topology of microbial communities in the major gut compartments of Melolontha melolontha larvae (Coleoptera: Scarabaeidae). Appl. Environ. Microbiol. 71: 4556-4566.

Gilliam, M. 1997. Identification and roles of non-pathogenic microflora associated with honey bees. FEMS Microbiol Lett. 155: (1), 1-10.

Kwong, W.K., Moran, N.A. 2013. Cultivation and characterization of the gut symbionts of honey bees and bumble bees: description of Snodgrassella alvi gen. nov., sp. nov., a member of the family Neisseriaceae of the Betaproteobacteria and Gilliamella apicola gen. nov., sp. nov., a member of Orbaceae fam. nov.,Orbales ord. nov., a sister taxon to the order 'Enterobacteriales' of the Gammaproteo bacteria. Int J Syst Evol Microbiol. 63:2008-2018.

Losey, J.E., Vaughan, M. 2006. The economic value of ecological services provided by insects. BioSci. 56: 311315.

Nichols, E., Spector, S., Louzada, J., Larsen, T., Amezquita, S., Favila, M.E. 2008. Ecological functions and ecosystem services provided by Scarabaeinae dung beetles. Biol. Cons. 141: 461-1474.

Rajagopal, R. 2009. Beneficial interactions between insects and gut bacteria. Indian J Microbiol. 49:114-119.

Shayne, J.J., Hugenholtz, P., Sangwan, P., Osborne, C., Janssen, H.P. 2003. Laboratory cultivation of widespread and previously uncultured soil bacteria. Appl. Environ. Microbiol. 69: 72117214.

Sriram, S., Savitha, M.J., Rohini, H.S., Jalali, S.K. 2013. The most widely used fungal antagonist for plant disease 
management in India, Trichoderma viride is Trichoderma asperellum as confirmed by oligonucleotide barcode and morphological characters. Current science. 104: (10)

Tang, X., Freitak, D., Vogel, H., Ping, L., Shao, Y, Cordero, E.A., Andersen, G., Westermann, M., Heckel, D.G., Boland, W. 2012. Complexity and variability of gut commensal microbiota in polyphagous lepidopteran larvae. PLoS One. 7: (7), e36978.

Vasanthakumar, A., Delalibera, I., Handelsman, J., Klepzig, K.D., Schloss, P.D., Raffa, K.F. 2006. Characterization of gut-associated bacteria in larvae and adults of the southern pine beetle, Dendroctonus frontalis Zimmermann. Environ. Entomol. 35: 1710-1717.

Zhang, H. and Jackson, T.A. 2008. Autochthonous bacterial flora indicated by PCR-DGGE of $16 \mathrm{~S}$ rRNA gene fragments from the alimentary tract of Costelytra zealandica (Coleoptera: Scarabaeidae). J. Appl. Microbiol. 105: 1277-1285.

Zheng, H., Nishida, A., Kwong, W.K., Koch, H., Engel, P., Steele, M.I., Moran, N.A. 2016. Metabolism of toxic sugars by strains of the bee gut symbiont Gilliamella apicola. MBio. 7: (6), e01326-16.

\section{How to cite this article:}

Surabhi Kumari, R. Rangeshwaran, A.N. Shylesha and Jagadeesh Patil. 2018. Gut Microflora Associated with Adult Dung Beetles Oniticellus cinctus and Onthophagus dama (Coleoptera: Scarabaeidae). Int.J.Curr.Microbiol.App.Sci. 7(03): 847-854.

doi: https://doi.org/10.20546/ijcmas.2018.703.099 